\title{
Mediação: esporte rendimento e esporte da escola
}

Ao longo de três números a revista Movimento promoveu a discussão do tema Esporte na escola e esporte de rendimento. Os colegas Bracht, Kunz (2000, 12,) Gaya, Taffarel (2000/2, 13), Stigger e $\operatorname{Vaz}(2001 / 1,14)$ escreveram artigos cientes de estarem participando da discussão de um tema polêmico, embora sem uma estrutura que permitisse a organização da polêmica. Como resultado, os artigos não possuem eixos ou questões comuns e, mesmo, alguns dos artigos apenas tangenciam o tema polêmico. Estaríamos, portanto, diante de uma polêmica entre aspas, como escreveu Vaz. O leitor tem a impressão de que cada autor desenvolveu seu tema independentemente. Creio que o texto de Bracht e o de Gaya, que assumiu um caráter aberto de debate com Bracht, juntamente com o de Taffarel, podem ser considerados como dentro do tema. ${ }^{1}$ Os demais textos, embora emitam sinalizações importantes sobre pontos específicos, podem se considerados como externos à polêmica. Deixarei por essa razão para o final o comentário de alguns aspectos desses textos.

Fui convidado pelos editores para "mediar" as posições. Declaro que não sei muito bem o que significa, neste caso, mediar e também, que relidos os trabalhos a tarefa pareceu-me de fato bastante difícil. Tive vontade de renunciar ao amável convite, mas fiquei empenhado pelo compromisso com a palavra dada.

Mediar significa estar no meio, com os artifícios técnicos que realizam a comunicação mediada. Conceitos e construções de pensamento funcionam como mediadores entre teorizações ou descrições de níveis do real. Mediar também signifi- ca realizar operações simbólicas para que conhecimentos ou saberes de um campo se transformem em produtos ou processos inovadores de intervenção ou sejam levados como crenças ou orientações para a ação do não especialista. Por último, mediar significa tentar levar opositores ou antagonistas a algum tipo de acordo, como na mediação dos conflitos ou processos jurídicos. Acredito que seja este último significado o que orientou o pedido dos editores da Revista Movimento. Suponho que eles pretendem contribuir com acordos para a ação e penso que esses acordos estão presentes nos autores do tema polêmico. Contudo, além ou aquém deles, apresentam variações significativas que, com freqüência, os levam do tratamento do tema para o confronto ou debate intelectual. E um lugar comum afirmar que os intelectuais tendem a distinguir-se e, eventualmente, a formar "igrejinhas" lideradas por figuras que tenham carisma de idéias e por vezes de personalidade. Clérigos e intelectuais, como foi repetidamente salientado, têm muito em comum. Diferem do experto ou do especialista, pois este geralmente está preocupado por satisfazer a demanda sem interrogar-se sobre a justiça, sobre o valor dos objetivos para os quais deve inventar os meios de realização.

Diante das semelhanças e das diferenças, eu, o comentarista, sou levado pela tentação de dois erros opostos: remarcar as diferenças ou enfatizar as semelhanças. Creio que os autores sentir-seiam pouco confortáveis tanto num caso como no outro. No primeiro caso me acusariam de enfatizar a divergência dos argumentos, esquecendo seus pontos comuns; no segundo, diriam 


\section{$\rightarrow$}

que estou esquecendo as singularidades de seus argumentos resgatando apenas os pressupostos partilhados. Como minha tarefa é de mediação não realizarei citações de textos fora do debate, nem dos meus próprios. Apenas conversarei com os autores.

Uma mediação equânime significaria um distanciamento absoluto que permitisse mapear as semelhanças conservando as diferenças. Não creio ser capaz de manter distanciamento tão angélico. Pessoalmente, identifico-me com aqueles que pensam e sentem-se dentro da cidade e não com os que o fazem como se estivessem no topo da montanha que a domina. Nas ruas da cidade podemos conversar para entender o que Trata-se de acontece. No topo da argumentar, de montanha somos donegociar, de conciliar fazermos as leis e temos para podermos viver boas possibilidades de juntos. Contudo, isto ofrer do complexo de não significa que a Moisés. Minha mediação crítica desapareça. \$erá portanto uma converCreio que ê nesse \$a imaginária. Porém, contexto que ela pode partir do endereço que ganhar seu фcupo na cidade e não de verdadeiro papel nenhum lugar especial sendo, portanto, mais um dos tantos que contribuem para que a cidade caminhe no sentido da ordenação. Então, falarei das posições dos autores a partir de minha própria posição que é favorável ao esforço de estabelecer acordos no campo da intervenção. Sem acordos não há eficácia simbólica e, sem ela, não há ação eficaz. Todavia, é importante que seja dito que minha posição foi (re) trabalhada a partir das posições dos participantes do tema polêmico. Sou dos que opinam que no debate ou na polêmica elaboramos permanentemente nossa posição a partir do entendimento das dos outros. Se a intenção fosse apenas conservar a própria posição sem, minimamente, aperfeiçoá-la, significaria que o debate foi estéril. Como orientador observo e até pergunto a meus orientandos sobre suas mudanças no processo de pesquisa. Considero que a mudança de orientador e orientando é um dos eixos no diálogo do processo de pesquisa.

Creio que Bracht faz no seu texto dois movimentos: um de demarcação, e o segundo de aproximação. Creio que o objetivo do primeiro movimento é o de conservar o público interno, as adesões já conquistadas, para a sociologia crítica da educação e do esporte. Bracht produz sua demarcação a partir de três axiomas que podem ser contraditórios: o primeiro é o do abandono da escola pelo projeto neoliberal, ${ }^{2}$ o segundo é o do papel conservador da escola e o terceiro a contribuição desse papel do esporte na escola. Creio que a sociologia crítica de Bracht quando usada com função demarcatória parece remeter ao essencialismo que ele tanto critica: escola e esporte seriam essencialmente conservadores. Bracht deveria levar a sério as contribuições de Stigger sobre a heterogeneidade das práticas esportivas, as de Vaz sobre as interpretações do esporte que não se situam na perspectiva da sociologia crítica e as de Taffarel, no sentido de que o esporte não têm nada essencialmente bom ou mau. Em outros termos, para Bracht continuar validando a funcionalidade do esporte para a reprodução deveria discutir com os autores que lhe atribuem aspectos positivos nem sempre funcionais, no sentido da acomodação ou adequação reprodutora. Creio que o texto de Taffarel é atravessado pelo reconhecimento dos efeitos contrários e contraditórios do esporte rendimento e sua impossibilidade, ética e prática, de ser posto no contexto escolar, do modo que ele é.

Contudo, depois de demarcar, Bracht assume a vontade de aproximação mediante a eliminação de mal-entendidos. Incita-nos pelo bom caminho no sentido de estarmos cientes das finalidades ou valores da intervenção no campo do esporte e da necessária subordinação dos processos técnicos aos mesmos, mediante a crítica da suposta auto-evi- 


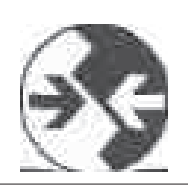

dência da razão instrumental, e continua relativizando, com muito bom senso, as posições extremas. Creio que trabalha na direção da prudência, pelo caminho do meio, para escaparmos de erros inversos e, neste sentido, eu o acompanho, embora a tarefa talvez seja mais difícil do que agir dogmaticamente. Creio que todos os participantes do debate estão em princípio de acordo: devemos tratá-lo pedagógicamente, tanto quanto devemos fazer isso com as matemáticas. Significa que temos que dar ao esporte da escola um sentido diferente daquele que possui o esporte rendimento e que não devemos nem podemos subordinarmos inconscientemente à técnica pelo seu valor. Entretanto, não podemos cometer o equívoco inverso de idealizar o lúdico nem abandonar o movimento pela reflexão. ${ }^{3}$

Gaya vai contra a aceitação de um ponto de vista dominante, no caso a sociologia crítica de Bracht, e reivindica a validade dos diferentes níveis de leitura e diferentes leituras do fenômeno esportivo. Em segundo lugar, argumenta sobre o caráter formativo e educativo do esporte de excelência, tal qual uma escola da vida. Gaya pretende convencer-nos sobre o valor formativo do esporte e isso o leva à defesa de uma essência positiva. Em segundo lugar, creio que perde de vista que o esporte rendimento se define na relação constitutiva entre esportistas e público, por isso igualamos esporte rendimento com esporte espetáculo. A fisiología do esporte não diz nada sobre o esporte rendimento, enquanto relação entre atletas e público, ela apenas nos fala do organismo submetido a esforços, por isso é um capítulo da fisiología do esforço e, mais para trás no tempo, da denominada fisiología do trabalho. A química das tintas usadas pelo pintor para fazer o quadro tem pouca ou nenhuma pertinência para falarmos da relação da obra com seu público. Creio que Gaya complica inutilmente o debate quando introduz discussões de essência, mais ainda, abandona seu próprio conselho para sermos prudentes. A essência é um consenso, propriedade específica do objeto porque dizemos que ela assim é, que muda em função de nossas mudanças no tratamento do objeto. Concordo, entretanto, sobre a possibilidade defendida por Gaya de que sob certas circunstâncias o esporte de excelência, possa ser educativo, mas essa não é sua essência! Creio que avançaremos se aceitamos que o esporte rendimento é uma realidade contraditória e que com ela devemos lidar educativamente. Prefiro adotar uma perspectiva pragmática, entro no debate como creio que o fazem Stigger e Vaz, com intenção de construir Creio que faz-se valorizar acordos que necessário esclarecer orientem a ação Assim. que vejo o conjunto creio que o objetivo dos autores como principal deva ser o de progressistas, criticos, estabelecer acordos para $a$ de esquerda, radicais ação. Kunz, em par- le en como queiram ser
ticular, defende o valor da ou como sensibilidade, da percepçã denominados e da intuição no agir esportivo como componente desse acordo. ${ }^{4}$ Procurarei manter-me dentro desta possibilidade do debate. Entendo que estamos diante de problemas e que devemos estabelecer acordos para enfrentá-los. Trata-se de argumentar, de negociar, de conciliar para podermos viver juntos. Contudo, isto não significa que a crítica desapareça. Creio que é nesse contexto que ela pode ganhar seu verdadeiro papel.

Creio que faz-se necessário esclarecer que vejo o conjunto dos autores como progressistas, críticos, de esquerda, radicais ou como queiram ser denominados. Compartilham a crítica do esporte e da sociedade, o que não significa que sejam contra o esporte e a sociedade, e todos pretendem gerar algum tipo de mudança que aproxime o esporte real do ideal e procuram o mesmo movimento, do real para o ideal, em suas considerações sobre a sociedade. Contrapõem-se, em bloco, àqueles que admiram o esporte como ele é e gostariam que a escola difundisse suas práticas tecnicamente orientadas para obtenção de resultados, despertasse vocações e se possível detectasse e encaminhasse ta- 
lentos para o esporte rendimento ou espetáculo. Rejeitam, portanto, trabalhar para promover o horizonte do esporte negócio, do esporte espetáculo ou rendimento. $\mathrm{O}$ fato de que não sejam contra, como afirma Bracht, e ao mesmo tempo que sejam críticos do esporte, provoca uma tensão em seus discursos que, às vezes, pode levar a posições que outros decodificam como contra o esporte. (Diria que grande parte das contraposições entre

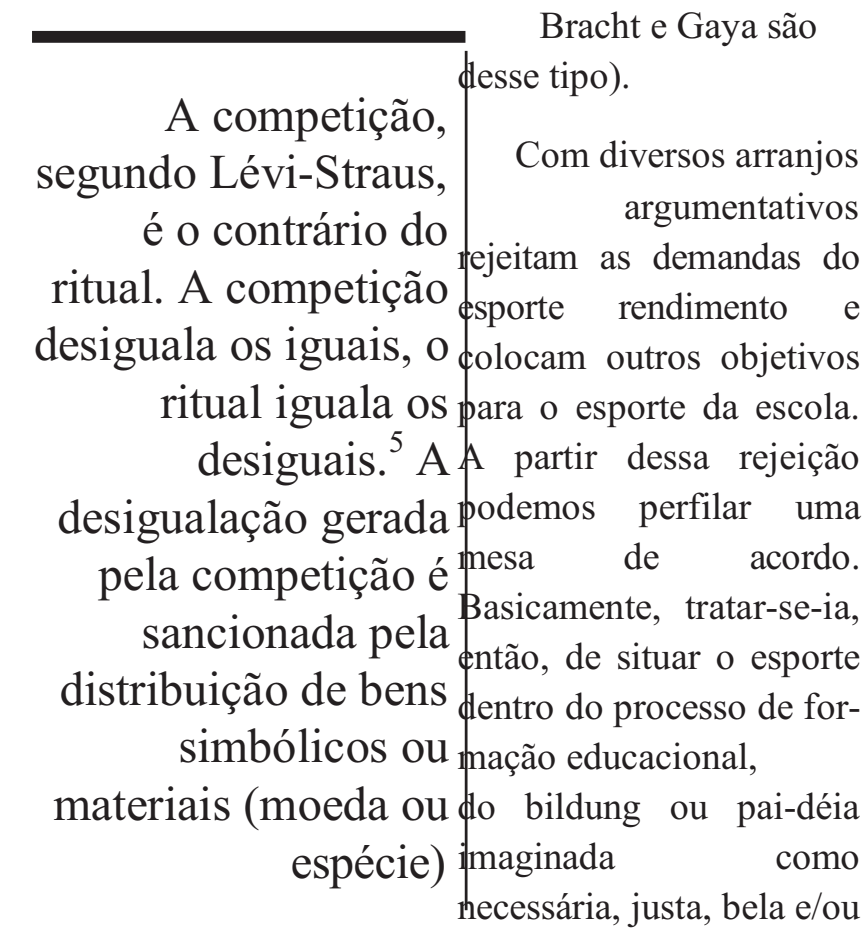

verdadeira. Creio que deveríamos partir deste acordo, embora de alta formalidade. Neste sentido, importa menos aquilo que o esporte rendimento é na sociedade e muito mais - como salientou Taffarel em seu artigo, seguindo a opinião de Parlebas - o que fazemos com ele no processo educacional. Sartre dizia alguma coisa semelhante: é menos importante aquilo que nos fizeram que aquilo que fazemos com o que fizeram de nós. Caso contrário, se importasse mais o que fizeram estaríamos renunciando a nossa própria intervenção no mundo. Este critério geral se aplica às ciências, à artes, às tecnologias, enfim, a tudo aquilo que por ser cultura a educação deve incorporar. Nenhuma dessas "incorporações" deve ser realizada como mera cópia dos univer- sos simbólicos e práticos de cada campo de produção cultural.

Há três pontos que devo considerar inicialmente para eliminar malentendidos. Primeiro: considero que a competição que se expressa em ganhar e perder é a alma do esporte. A competição, como alguma vez explicou Lévi-Straus, é o contrário do ritual. A competição desiguala os iguais, o ritual iguala os desiguais. ${ }^{5}$ A desigualação gerada pela competição é sancionada pela distribuição de bens simbólicos ou materiais (moeda ou espécie). Não consigo imaginar como realizar um esporte que não seja competitivo e desigualador. Podemos imaginar uma estrutura competitiva cuja desigualação seja sancionada apenas pela distribuição de bens simbólicos. De fato, acredito que essa seja a característica que define o esporte amador. $\mathrm{O}$ menor bem simbólico é a satisfação individual ou grupai em ter participado do jogo competitivo, o maior talvez seja a medalha Olímpica. Participar do jogo é importante em si mesmo, significa dizer, eu estive lá, fui parte da história. Creio que este é um tópico que gera malentendidos entre os educadores físicos. Temos que reconhecer que olhamos com admiração para o atleta que participou de uma Olimpíada, embora tenha chegado por último. O próprio fato de estar lá faz uma tremenda diferença, talvez não tenha sido o melhor, mas certamente era muito bom. Resumindo, proponho que falemos de esportista para nos referirmos à figura que participa ou está motivada para participar do esporte competitivo. Segundo: considero importante não perder de vista as atitudes dos atores esportivos. E freqüente que os esportistas entrem em competições sabendo que não poderão ganhar. Podem participar para acumular experiência, para superar seus próprios desempenhos anteriores ou para chegar a alguma etapa da seleção ou desigualação competitiva entre outros motivos. Os esportistas re-significam sua própria participação, estabelecendo objetivos e finalidades próprias, sob o pano de fundo da regra da competição. Os esportistas desenvolvem argumentos 


\section{$\rightarrow$}

que os "protegem" da perda da competição, (enquanto escrevo os flamenguistas celebram o jogo que lhes permite continuar na Primeira Divisão, embora entre os últimos classificados). Se não estamos dispostos a desenvolver esses argumentos, e entre eles os que permitem derivar "ganhos" da derrota, não poderemos estar no esporte. Nesse caso, eu sugeriria que nos dedicássemos a desenvolver rituais ao invés de competições e, se assim fosse, creio que a religião seria o campo natural de igualação ritual e que fracassaríamos se tentássemos dar essa função ao esporte. Terceiro: o fato de fazermos atividade física, de desenvolver nosso condicionamento físico não significa que sejamos esportistas no sentido estrito. Assim, posso imaginar atividade física escolar geradora de condicionamento sem competição. Durante meus anos da Escola Normal nas aulas de Educação Física fazíamos ginástica e danças folclóricas. Não tínhamos competição esportiva nem iniciação esportiva, talvez por falta de condições. Quarto: o fato que se trabalhe pela inclusão nas atividades físicas ou esportivas escolares não significa que todos queiram incluir-se da mesma maneira, participar com a mesma intensidade e, mesmo, podem existir aqueles que não desejam ser incluídos. A possibilidade não pode ser confundida com sua realização.

Creio, portanto, que se há atividade esportiva na escola algum grau de competição terá que estar presente. Contudo, a existência de algum grau de competição não implica que a mesma seja o objetivo principal da atividade esportiva na escola. Assim, o esporte deveria estar articulado, estruturado no projeto da escola. Não como atividade agregada, como elemento de uma soma, porém como dimensão e parte de um todo vivo e em movimento.

Emergem assim três questões que deveriam ter sido eixos explícitos do debate para gerar as respostas dos participantes: a) quais as finalidades (valores e objetivos) dos esporte da escola, b) quais os meios de ensino-aprendizagem não contradi- torios com essas finalidades e c) como se articulam as ações do esporte da escola com o conjunto de suas finalidades e meios. Importa destacar que, se um dos objetivos da educação é o desenvolvimento da "autonomia moral e cognitiva", por exemplo, não poderíamos agir com processos de ensino-aprendizagem que reforcem a "heteronomia". Creio que todos os participantes concordam com essa posição que, em outra linguagem, é um dos eixos da intervenção de Kunz.

É necessário ainda estabelecer outro tópico de acordo. A educação tem uma semelhança profunda com a história. Sabemos vivencialmente que a história é diferente, que muda, porém também que estamos na mesma história. A história é tensão entre a continuidade e a mudança que formam seus fios entremeados, e cuja sua distinção é uma tarefa complexa e difícil que persegue historiadores e analistas sociais. Ambas, conti-O menor bem nuidade e mudança, simbólico é a resultam das lutas dos satisfação individual atores sociais (indivíduos, ou grupal em ter classes, elites ou grupos participado do jogo em função da teoria da história posta em competitivo, o maior ação por quem construiu a talvez seja a medalha narrativa) dependendo das Olímpica configurações, do estado e dinâmica dos campos, das conjunturas ou da consciência possível. A educação será portanto um misto de conservação e transformação. Ela jamais poderá ser absolutamente nova ou absolutamente conservadora. A ansiedade pelo "absoluto" forma parte da vontade totalitária. Não podemos compactuar com o totalitarismo em nenhum campo, menos ainda com o absolutismo educacional, uma de suas variantes.

A proporção na formação do bolo educacional de conservação e mudança é um poderoso critério para organizarmos o entendimento de seus 
projetos ou propostas. Em sociedades plurais modernas, é mais ou menos evidente que os projetos educacionais devem apresentar diferenças de "personalidades" (identidades culturais e procuras de construção pessoais) para atender as demandas diferenciadas, embora por vezes de perfis difusos ou pouco explícitos. A educação tem umado, essas diferenças A educação tem uma de personalidades não semelhança profunda podem renunciar à com a história. personalidade comum ou Sabemos à formação do cidadão. vivencialmente que a Surge nova complexidade, história é diferente, $\begin{aligned} & \text { porque o projeto de cada } \\ & \text { escola deve tanto }\end{aligned}$ que muda, porém responder às exigências do também que estamos ideal

na mesma história da sociedade global, expresso, por exemplo, na

formação do cidadão, como das particularidades demandadas pelas diferenças que compõem a sociedade plural.

Creio que ao longo dos últimos cento e cinqüenta anos ocorreram várias coisas importantes com o esporte de rendimento ou esporte espetáculo. A primeira e fundamental é que o gosto pelo esporte rendimento se expandiu por diferentes classes e culturas. Algumas de suas variações, como futebol, chegaram a contar com bilhões de apreciadores. Houve um considerável investimento, material e simbólico, para construirmos o nosso gosto pelo esporte, e o jornalismo jogou um papel de primordial importância nessa construção que incidiu sobre o crescimento e importância do próprio jornalismo. Gostamos de esportes particulares (prática ou espetáculo) porque que eles nos divertem, nos emocionam, enfim, em minhas palavras, nos tiram do tédio muito mais do que ajudam a evadir-nos da realidade. ${ }^{6}$ Entremeada com a construção do gosto, formou-se um significativo campo de negócios esportivos e um campo não menos significativo de construções identitárias de distinção e participação (de classe, de estamento, locais, nacionais, etc). Sem gosto e emoção não teríamos um mundo de negócios. Creio também que sem identidades não teríamos os níveis de emoção que temos. De fato, ter uma identidade é participar de um mundo simbólico e social e, sobretudo, de afetos identificadores. Duas observações apoiam essa consideração: raramente torcemos sozinhos, preferimos torcer juntos e desconfiamos daquele que gosta do esporte sem torcer por algum dos adversários. Será que ele gosta mesmo? Por último, o esporte tornou-se um mercado de emprego e passou a ser visto como uma das escadas possíveis de mobilidade social.

Crianças e jovens das camadas populares sonham em serem esportistas. Como outros sonham em serem médicos, advogados, artistas ou, mesmo, donos de supermercados, como Manolo, o famoso "amiguito" da Mafalda. Sonham em fazer o que gostam, em ganhar dinheiro ou em serem reconhecidos. Os adultos repetem em coro que realizar esses sonhos não é fácil e que ainda é muito mais difícil sem escola. Assim, todos esperamos que a educação faça alguma coisa pela realização dos sonhos. Admiramos as pessoas que realizam seus sonhos, gostaríamos de ser como elas, gostaríamos de ocupar o lugar delas. Depois de tudo, Pelé é rico, reconhecido e fez aquilo que gostou, jogar futebol, de forma impecável. (O "sonhar" é uma figura fortemente presente em Paulo Freire, não há mudança sem haver sonhado e criar sonhos em conjunto é tremendamente importante).

Gosto, acumulação e reconhecimento são orientadores tremendamente forte da conduta. Com ênfases variadas, entendemos que a realização passa por misturas dessas dimensões. O esporte espetáculo tornou-se um campo respeitado e desejado de realização dos sonhos de construção dos "eus", ao lado dos negócios, da política, das ciências e das artes, entre outros. ${ }^{7}$

Eu diria, Bracht, que você pode propor o esporte da escola com os valores e modalidades que você quiser, entretanto, se ele for chato, se não emoci- 


\section{$\rightarrow$}

onar, se não for uma atividade antitédio e se não se situar no horizonte dos sonhos dos praticantes, você terá pouquíssimos alunos em qualquer sistema que valorize a liberdade de escolha das atividades escolares. Se a atividade proposta é um tédio e se não se cruza com os sonhos apenas a repressão fará que os estudantes participem. Se a participação é determinada pela obrigação normativa podemos obter como resposta a presença ausente, participação muito pequena, com "p" minúsculo. Estou dizendo então que o esporte lida com o estético, com gostos e emoções, do corpo e da performance esportiva, e que não podemos esquecer essa dimensão, talvez hoje a principal.

Concordo, no entanto, com Bracht nas rejeições éticas e parciais que realiza. Veja-se os exemplos de seu artigo, da "malandragem" que burla ou usa a regra a seu favor e das "crenças tontas" como pensar que Deus nos ajudou no jogo. Creio que a educação deve ter um tom kantiano, presente nos autores que Bracht menciona no campo da ética. E nossa obrigação salientar que a "malandragem" é uma crença, de difícil justificação, e que se empenha contra a qualidade do jogo. $\mathrm{O}$ malandro esquece que os outros também podem ser malandros. Num mundo de malandros não poderíamos confiar em ninguém. Como viver nesse mundo, sem confiança ontológica, como diria Giddens? Um mundo de malandros pareceria ser uma variante do mundo hobbesiano, da guerra de todos contra todos. Esse mundo demanda um poder de hetero-controle forte, quase absoluto. O mundo dos malandros solicita um ditador. O que agradece a Deus por haver vencido (Marcelino no exemplo de Bracht), tem uma ação bem diferente de agradecer a Deus porque ninguém se contundiu, tem uma idéia de Deus bem utilitarista e individualista. Não creio que Deus concorde com ele. E se concorda, então, nossos deuses são diferentes. $\mathrm{O}$ meu não é nem a favor nem contra o Flamengo ou o Palmeiras. Pode até assistir e gostar do jogo, mas deixa que nossa habilidade defina o placar e olha com mui- ta ternura para os que perderam o jogo. Gaya, pela sua vez, poderia contar histórias de autosuperação, de solidariedade, de companheirismo e de altruísmo no esporte. Ambos, poderiam passar a vida colhendo exemplos a favor ou contra o esporte. Eu insisto juntamente com Taffarel, é o que fazemos com ele e não o que ele é. Temos então que realizar nossos "passes" éticos; mas, isso, em toda a escola e de forma contextualizada em cada atividade ou disciplina. Sob o ponto de vista ético, esporte, matemáticas, história ou português, entre outras disciplinas ou atividades, não são diferentes. Devemos promover na formação do

professor a competência

filosófica e ética. Se Gostamos de apenas uma minoria pode esportes particulares lidar com as (prática ou considerações de Appel e
outros, será muito difícil espetáculo) porque outros, será muito difícil que eles nos
transformar a reflexão que ética em componente do divertem, nos processo educacional.emocionam, enfim, Preocupa-me, em relação em minhas palavras, ao contexto da formação nos tiram do tédio dos educadores físicos, o muito mais do que peso desproporcional que ajudam a evadir-nos assume o conhecimento da realidade pa-me que a notícia dominante seja a última receita para desenvolver os músculos e o desprezo pelas aquisições do passado. Preocupa-me a moda construída sem fundamentos teóricos sólidos e empíricos válidos. Creio que todos os que participaram da "polêmica" partilham dessas preocupações.

Kunz concentra o olhar, a partir de seu referencial fenomenológico, para o valor da autonomia da aprendizagem dos esportes. O esporte é para Kunz um bom lugar para os estudantes desenvolverem sua capacidade de agir, de fazer, de sentir, de praticar, de acertar e também, eu diria, de errar. 


\section{(3)}

Valoriza os modos ativos e autônomos de apreender em detrimento dos comandos externos e das instruções detalhadas que poderiam reduzir as capacidades de perceber e se movimentar. Partilho com Kunz a resistência à heteronomia no processo de ensino aprendizagem e sua valorização do fazer, do sentir, do agir. ${ }^{8}$ Creio, também que Kunz e eu concordamos num ponto: se estamos com um problema temos que conversar sobre ele. Creio que na polifonia das vozes podemos encontrar a inovação, ainda quando se trate de coisas técnicas como o treinamento. Por essa razão escrevi com Yara Lacerda sobre Phil Jackson, para chamarmos a atenção sobre o lugar que, em um time várias vezes campeão de basquetebol, ocupavam valores como compaixão e meditação: o lugar da espiritualidade. ${ }^{9}$ Estamos de acordo, o esporte não é, nem deveria ser, somente técnica e vontade de vencer. E também lugar de reconhecer que quando perdemos aprendemos e crescemos se conversarmos, se formos compassivos, se tivermos piedade de nós e dos outros. Creio que neste ponto também concordam os outros autores e, especialmente, Gaya.

A vontade de demarcação de Bracht fica clara em dois aspectos que aparecem com destaque em outros dois autores da polêmica: Stigger e Vaz. O primeiro, combate a sociologia crítica a partir da homogeneidade que a mesma realiza do esporte. Para Stigger, o esporte seria um campo heterogêneo de finalidades ou intencionalidades e também de relações sociais. Propõe um olhar mais antropológico que compreendendo a especificidade de diversos casos leve para um enriquecimento conceituai que permita perceber as diferenças das práticas. Contudo, Stigger pensa a partir de um material etnográfico muito rico de orientações de adultos, não de crianças e jovens. Porém, creio que também no caso, agir, movimento, diversão, sociabilidade, prazer de estar juntos entre outras orientações têm significativo peso.

Vaz, por seu lado, apresenta um campo teórico cindido, onde a sociologia crítica não apenas perde espaço para outras visões, como a de DaMatta e Elias, por exemplo, que reconhecem a positividade dos esportes (educação política e autocontrole, entre outros valores), como também não consegue explicar o fato das técnicas de treinamento terem sido supervalorizadas no socialismo real. Nos autores tratados por Vaz, a interpretação cai para o lado da "civilização" em lugar da "repressão" ou "reprodução".

Ambos, Stigger e Vaz, procuram apresentar os argumentos contrapostos e relacioná-los com descrições empíricas e narrativas sobre o esporte. Diria para Stigger que nos casos que ele analisa sempre há a procura da diversão, da emoção, de passar um bom momento, enfim, de situar-se no mundo oposto ao do tédio. Também é certo que quando os atores tomam uma decisão, tem uma forte tendência a gerar argumentos que reforcem a mesma. Assim, se comecei a jogar futebol porque me diverte posso, sem muito esforço, encontrar que ele promove a amizade, a sociabilidade, a ajuda mútua, a saúde, o antiestresse e tantas outras funcionalidades ou valores que, rapidamente, podem ser vistas como intencionalidade ou finalidades.

Com Vaz caminhamos muito próximos, ambos temos tentado conciliar. Isto significa que talvez estejamos lutando pela prudência, pela temperança dos extremos, pelo encontro de alternativas. Estamos lutando muito mais por acordos sobre a boa vida que por uma definição da verdade. Concordamos, creio que todos, que a boa vida não pode ser tal se a maioria está fora dela. A hiper valorização da técnica, contudo, não nos pode levar a uma hiper valorização romântica da destecnificação; a hiper valorização da ciência não deve fazer que nossa reação seja uma hiper valorização do mito, pois, no fundo, a primeira hiper valorização significa o mito da ciência. Assim, a reação seria autocontraditória, ataca o mito com outro mito. Pretendemos, mais modestamente, embora seja uma tarefa difícil, apenas colocar a 
ciência no seu lugar. ${ }^{10}$ Temos que mediar e encontrar algum equilíbrio. Creio que no fundo não queremos ficar apontando com o dedo e dizendo: vejam o que fizeram com o mundo, vejam o com fizeram conosco, vejam o que me fizeram! Creio que nos situamos como dançarinos a beira do abismo e dizemos, talvez como Sartre, o que importa é aquilo que faremos com o que nos fizeram! Penso tudo isso, insisto, andando pela cidade e não a partir da montanha!

As ciências, as artes, os esportes não podem estar fora da escola. Como não podem ficar fora da escola tarefas importantes como cuidar da natureza, da cidade, do lar, das crianças, dos fracos, dos doentes e dos velhos. Defendo, por isso, que os bolsistas da pós-graduação tenham a obrigação de devolver à sociedade o que esta faz por eles, cuidando dos aspectos acima mencionados, como prática de idéias. Concordo com Bracht no sentido de que devemos no esporte escolar desenvolver a reflexão ética e com Sigger e Vaz em que podemos reforçar os valores positivos do esporte ao mesmo tempo que criticamos os negativos de forma prática, talvez como diria Gaya. Se fizermos isso, não haverá problemas em organizarmos torneios e mostrarmos com modesto orgulho os nossos troféus. Concordo com Kunz, quando afirma que trata-se de modificar as práticas escolares e de treinamento e irmos na direção da apropriação dos processos que reforçam a autonomia do fazer. Sua idéia é boa, temos que ajudá-lo a aperfeiçoá-la. Este é um dos pontos de acordo possível se melhorarmos seus exemplos e se formos cientes dos efeitos de suas propostas. Estou tentando afirmar que temos que gerar a prática de idéias e formas de conversação que nos permitam agregar acordos para a ação.

\section{Notas}

${ }^{1}$ Suponho que o leitor já leu os textos dos participantes do tema polêmico. Se não fez isso seria bom que o fizesse antes de continuar. $\mathrm{Eu}$ concordo com muitas das afirmações feitas por Taffarel. Sua intervenção, entretanto, é realizada dentro do modelo tradicional do intelectual leninista do partido. Vai da estrutura para a conjuntura, da luta de classes para a relação docente aluno, do modo de produção para a situação concreta, etc. Fiquei convencido da precariedade dessa forma de proceder há mais de 20 anos atrás. Lembro do Rio Grande do Norte quando um técnico marxista explicava ao camponês como a exploração imperialista, capitalista e a luta de classe tinham feito que perdesse sua colheita por falta de chuva. Semanas mais tarde perguntei ao camponês em quem tinha votado. Disse-me o nome e o motivo: votou no candidato que tinha prometido fazer um açude na sua propriedade. Temos que enfrentar os problemas aqui e agora e, para isso as análises tradicionais marxistas se revelaram muito pouco eficientes. Estamos falando das possibilidades de ação, não necessariamente da verdade. De fato, domina no marxismo pensar a ação a partir da representação ou da teoria elaborada pela vanguarda intelectual, segundo o modelo desenvolvido por Lenin no Que fazer. Taffarel pertence a essa tradição. Segundo Lenin, o proletariado apenas pode desenvolver "teorias reformistas", e é tarefa dos intelectuais fazer a "teoria revolucionária". Creio que Taffarel continua pensando desse modo, então, apenas mencionarei alguns acordos que temos de "bom senso".

${ }^{2} \mathrm{O}$ apelo a uma suposta posição liberal do governo nas políticas públicas, especialmente em campos como educação e saúde, é altamente discutível em termos conceituais e práticos. Assim como há alguns anos atrás se atribuía todos os males à ditadura, atualmente o fantasma da vez é o neoliberalismo. Um mecanismo desta natureza é muito cômodo, contudo, fecha as possibilidades de pensar e agir. Creio que isso leva a Bracht a beirar perigosamente 


\section{(}

a autocontradição: se a escola é estratégica para a reprodução, porque o projeto liberal a abandonaria? Bracht afirma essas duas proposições ao mesmo tempo sem maior elaboração.

${ }^{3}$ Não estou convencido, como Bracht parece estar, de que "pedagogizar o esporte tornou-se um problema para o sistema esportivo, porque coloca nesta prática elementos que acabam entrando em confronto com os princípios, com a lógica que orienta a ações no âmbito esportivo". Creio que Bracht teria que desenvolver elementos teóricos e empíricos mais finos para fundamentar essa afirmação. Há escola privadas que promovem as escolinhas (pagas por fora) e mantém a educação física (incluída na mensalidade) por uma razão muito simples: nem todos os alunos querem praticar esporte dentro da "técnica" nem aspiram tornar-se esportistas. Creio que Bracht sofre de uma forte atração pela demarcação.

${ }^{4}$ Creio que o trabalho de Kunz merece uma reflexão detida que escapa ao escopo da mediação que estou realizando, tanto em relação aos fundamentos filosóficos quanto as suas conclusões. O título de seu trabalho Esporte: uma abordagem com a fenomenología, implicaria que a fenomenologia é uma técnica, um instrumento? Não haveria no caso uma "intelectualização" semelhante àquela que crítica no treinamento. Contudo, considero que Kunz está apontando perspectivas de trabalho que, em princípio, considero atraentes.

${ }^{5}$ Então, teríamos em termos de Kunz \& sobrepujança e a comparação objetiva. Observo que o atleta pode sobrepujar a seus concorrentes sem, no entanto, destacar-se na comparação objetiva. A comparação objetiva parece apenas operar quando temos relógios e fitas métricas, é de muito difícil realização nos esportes coletivos e artísticos, que exigem júris de especialistas. Há uma força estética no esporte, tanto nos corpos como nos movimentos, que devemos pensar melhor pois se tornam ideais ou fantasias de identificação. Creio que no campo do esporte passamos de valorizações éticas para estéticas. Bracht e Gaya ainda estão dominados pela percepção da eticidade no esporte. Se o que principalmente se admira é a performance esportiva, o desempenho, o virtuosismo do gesto, não estaríamos diante do esporte como manifestação de arte popular do mundo "pósmoderno"? Se for assim, o domínio técnico e a "genialidade do artista" não seriam elementos constitutivos? Teríamos, então, que trabalhar as relações entre ética e estética nos esportes?

${ }^{6}$ Observo que o ato de gostar e a formação dos gostos são temas básicos da estética.

${ }^{7}$ Creio que os participantes da polêmica escrevem para serem reconhecidos e possivelmente porque gostam da atividade intelectual, de brincar com a combinatoria que a fundamenta, como diria Pareto. Talvez apresentem-se como não estando orientados pela acumulação, contudo, por mais baixos que sejam os salários universitários estamos todos dentro do 1 ou $2 \%$ da população economicamente ativa que tem maiores ganhos. Para os que estão dentro do Brasil brasileiro não é pouca coisa.

${ }^{8}$ Tenho algumas dúvidas sobre a possibilidade de fundamentar via tradição fenomenológica as propostas de Kunz e, em segundo lugar, creio que suas conclusões não se derivam claramente de seus argumentos fenomenológicos. Contudo, não creio que seja esta a oportunidade de discutir essas questões pois provocaria um desvio de meus objetivos de "mediação".

${ }^{9}$ Tenho a sensação de que Kunz para apresentar suas propostas homogeneiza e estereotipa tanto a técnica quanto a figura do técnico. Parece-me difícil encontrar técnicos que não valorizem a intuição, a sensibilidade e a percepção do atleta. Também me parece difícil encontrar técnicos que não valorizem o fazer como meio de desenvolvimento do atleta. Mais ainda, meu relacionamento com os técnicos me leva a pensar que eles são muito mais práticos interessados em resultados que intelectuais preocupados pela racionalização e verdade. Eu os vejo como membros de uma família dentro da qual tentam inovar para ganhar. 


\section{$\theta$}

Os colegas autores dos textos parecem partilhar uma tremenda vontade de colocar a técnica no seu lugar, não de eliminá-la. Não sei se para trabalhar nessa direção Adorno, por exemplo, muito utilizado por Vaz, seja um bom companheiro de rota. Percebo uma quebra entre as opções teóricas e as vontades do caminho da prudência, da boa vida e de outras alternativas enunciadas pelos autores. Contudo, o problema da técnica mereceria um debate nele focado. 
